\title{
Educators discussing ethics, equity, and literacy through collaborative annotation
}

\author{
Jeremiah H. Kalir \\ University of Colorado Denver
}

Joe Dillon

Aurora Public Schools

Manuscript accepted for publication in:

K. Hawley (Ed.), Ethical dimensions of teaching digital literacy. Lanham, MD: Rowman \& Littlefield.

Correspondence concerning this manuscript should be addressed to:

\author{
Jeremiah H. Kalir \\ University of Colorado Denver \\ School of Education and Human Development \\ 1380 Lawrence St., Suite 645 \\ Denver, CO 80204 \\ (303) 315-0034 \\ remi.kalir@ucdenver.edu
}


Where might educators read about the "precarious public" of American Muslim youth (Shresthova 2016) and discuss how youth media practices and online identities inform learning inside and outside of school?

How can educators learn of media injustice patterns that disproportionately affect students of color and discuss how best to support "Black youth use [of] social media as counterspaces" (Baker-Bell, Stanbrough, and Everett 2017, 130) through critical media literacy?

And in what ways might educators learn from colleagues who have recognized their own pedagogical limitations and, subsequently, have crafted literacy education as a critical practice that "examine[s] racial injustice, class exploitation, gender expectations, sexual identity, gentrification, solidarity, and more" (Christensen 2017, 17)?

If educators - across grade levels and disciplines - are to teach about ethical digital literacy practices, they must seek out, and then participate in, ethically-oriented professional learning. Through ongoing participation, educators must practice digital literacy in professional learning that explores and debates ethical issues. An ethical stance toward digital literacy cannot solely be concerned with the development of technical skills. Rather, any stance toward ethical digital literacy must cultivate social dispositions toward equity and encourage critical political agency.

By participating in professional learning about ethical digital literacy practices, educators should develop fluency among their everyday texts, contexts, and technologies. Such professional learning must engender concern for the wellbeing of others, encourage honest interrogation of privilege and power, and shape more equitable educational and social futures. Educators must endeavor to craft their own ethical stance toward digital literacy if they are to teach at the intersection of ethics, equity, and literacy in a digital age. 
This chapter describes educator professional learning as nurtured by an open, ongoing initiative that encourages ethical digital literacy practices. Specifically, this chapter concerns educator learning as interest-driven, openly networked, and oriented toward educational equity (Watulak et al. 2018). For educators to learn about digital literacy, educators must also participate in and regularly practice digital literacy. Such practices should advance an ethical stance. And projects, like the one featured here, can help to open reflective spaces whereby educators' develop ethical and moral stances toward their practice.

A more ethical stance toward digital literacy transcends the mere use of everyday technology and promotes a robust understanding that tools and networks can highlight inequities, can also exacerbate division and harm, and may also help build solidarity in response to social and political concerns (e.g., Morris and Stommel 2018). In order for learners of all ages to practice more responsible and ethical digital literacy - and whether in school or in their communities, and whether as motivated by academic interest or civic advocacy - it is necessary for educators to participate in their own ethical and equity-oriented professional learning.

This chapter is co-authored by organizers of the Marginal Syllabus, a public initiative that, since 2016, has convened and sustained online conversations with educators about equity in education through open and collaborative web annotation (Kalir 2018; Kalir and Perez 2019). The three articles featured at the beginning of this chapter - all of which address ethics, equity, and forms of digital literacy - were included in the Marginal Syllabus to inspire educators' collaborative discussion and professional learning.

In describing how the Marginal Syllabus encourages educators' ethical digital literacy practices, this chapter addresses two inquiry questions. First, how might professional learning opportunities, like the Marginal Syllabus, orient educators toward ethical digital literacy 
practices? And second, how might such professional learning help educators to develop their own ethical stance toward digital literacy practices?

Equity-oriented Professional Learning through Collaborative Annotation

What is the Marginal Syllabus? The name, design, and digital literacy practices defining this participatory and equity-oriented professional learning project are all intentional references to multiple interpretations of the word marginal.

The Marginal Syllabus partners with authors - many of whom are themselves educators or professors - whose scholarship is contrary to dominant education norms. As educators read and discuss partner authors' texts, participating educators engage with perspectives that are marginal to the schooling status quo. Further, the Marginal Syllabus organizes publicly accessible conversations among educators that occur in the margins of online texts using open and collaborative web annotation technology. By opening up marginal online spaces, this project fosters public and democratic dialogue among educators (Mirra 2018).

The Marginal Syllabus also mediates educator conversation and collaboration via Hypothesis, an open-source web annotation technology that is marginal to commercial educational technology. When educators employ their digital literacy practices to participate in a Marginal Syllabus conversation, they are exposed to marginal perspectives, engage in marginal online spaces, and use marginal technology - all of which supports their professional learning.

In some respects, the Marginal Syllabus is like an online book group.

A book group can serve social and professional purposes. As a digital iteration of a book group, the Marginal Syllabus invites educators to construct meaning from partner authors' texts and then share personal and professionally-relevant responses by openly annotating both the readings and other educators' commentary. This approach positions educators as experts who 
can meaningfully contribute to lively and public conversation about learner needs and interests, school curriculum, and pedagogy. It also means educators can use annotation conversation to pursue interests about educational equity topics, ask questions, and offer critical commentary.

Notably, educator participation in the Marginal Syllabus' monthly discussions also mirrors constructivist approaches to K-12 literacy education, such as literature circles. Whether with educators in a book group or with students in a classroom literature circle, participants are encouraged to make meaning through their discussion of and with texts (Daniels 2002).

As of this writing, the Marginal Syllabus has organized over two dozen annotation conversations associated with three syllabi. The 2016-17 syllabi explored the relationship between educational equity and technology. The $2017-18$ syllabi addressed the theme of civic engagement. And the 2018-19 syllabi examined equitable literacy education. Hundreds of educators have participated in these annotation conversations, and many Marginal Syllabus conversations have been incorporated into teacher education courses and professional learning activities.

This initiative has grown thanks to commitments from multiple organizational partners, including the National Writing Project, the National Council of Teachers of English, the annotation nonprofit Hypothesis, as well as publishers of academic scholarship. Commitments by these partners to sustain Marginal Syllabus programming suggest the initiative has, among various outcomes, meaningfully encouraged educators to begin developing an ethical stance toward their digital literacy practices. But how so? What are some of the ethically-oriented qualities that distinguish educator participation in the Marginal Syllabus? 
The following four themes regularly emerge during educators' Marginal Syllabus conversation. These themes reveal tensions associated with the complexities of ethics, educational equity, and digital literacy.

Practice: Educators should identify, critique, and perhaps also disrupt digital literacy practices that are sanctioned and rewarded by traditional schooling. Educators should question what digital literacy practices count inside of school and discern the ways in which these practices may differ from literacies that youth develop and celebrate in their lives outside of school (e.g., Haddix 2018).

Expertise: Whose expertise defines digital literacy? Expertise in any particular digital literacy repertoire cannot be assumed, as both educators and learners are likely fluent in varied practices. Expertise also fluctuates across texts and contexts, as well as over time. Accordingly, curriculum and pedagogy cannot affirm a singular and codified understanding of expert digital literacy practices.

Technology: Technology use is not neutral. Beyond learners' differential access, the use of certain technologies may exacerbate inequities on account of designed affordances, privacy safeguards, and data ownership. Educators should examine how technology used in service of digital literacy amplifies means of expression and not surveillance, and affords creativity and social critique rather than restrictive control and compliance.

Space: Educators should create and hold open space - both embodied classroom space, as well as online and digital space - for learners to express their own digital literacies. Educators should examine the role that youth digital literacy practices can play in transforming conventional schooling spaces into more humanizing literacy spaces. 
As educators participate in Marginal Syllabus conversation, they publicly wrestle with their stance toward practice, expertise, technology, and space.

All of these tensions present myriad ethical challenges. For example, while some digital literacy practices may be useful in assisting learners to accomplish formal school objectives, educators should also honor and amplify divergent, and even subversive or contradictory, digital literacy practices that thrive beyond classroom walls. Naming and discussing such tension underscores how equity-oriented professional learning - as mediated by collaborative annotation in the Marginal Syllabus - can support educators as they work to adopt a more ethical stance toward digital literacy practices.

But what does this open annotation discussion really look like? How do educators actually wrestle with these tensions? And how do they openly dialogue about more ethical stances?

\section{Ethical Stances in a Marginal Conversation}

Dynamic ethical stances toward digital literacy and educator practice, expertise, technology use, and learning spaces are evident in the March, 2018 Marginal Syllabus conversation.

In March of 2018, Marginal Syllabus participants read, annotated, and discussed the article "The stories they tell: Mainstream media, pedagogies of healing, and critical media literacy," by partner authors April Baker-Bell, Raven Jones Stanbrough, and Sakeena Everett (2018). By identifying and critiquing patterns of media injustice, Baker-Bell and colleagues share their "pedagogies of healing" as a type of critical - and digital - media literacy that can encourage Black youth to rewrite racial justice narratives. 
As partner authors, Baker-Bell, Jones Stanbrough, and Everett shared their scholarship for public annotation and conversation, and they joined a webinar to describe their writing process and motivation with a small group of educators. Jones Stanbrough also engaged with educators in writing public annotations in the article's margins. To date, 20 educators have added 150 annotations to the article. In alignment with our four previously discussed themes, we highlight contributions to this conversation as evidence of how collaborative annotation can help educators develop their own stances toward ethics, equity, and literacy. ${ }^{1}$

Practicing Critical Media Literacy

Is it necessary for educators to practice a critical form of digital and media literacy? In their article, Baker-Bell and colleagues (2018) summarize six patterns of media injustice, or "how mainstream media humanize White people while simultaneously vilifying Black people and other people of color" (133). For example, a media double standard exists in regards to how White criminals are humanized through sympathetic media portrayals, whereas Black victims are frequently dehumanized.

As a means of learning about this critical media literacy, participating educators identified and analyzed media injustice patterns through their commentary about current events.

Annotator scirtenbaum, for instance, noted "when we see gun violence from white males, specifically, the conversation shifts towards mental illness, which both gives violent white criminals an 'out' and reinforces the misrepresentation that the mentally ill are violent." As with similar annotated commentary about events in Charlottesville, Ferguson, Baltimore, and Parkland, the conversation demonstrated how educators learned about media injustice by

\footnotetext{
${ }^{1}$ As noted, Marginal Syllabus conversations are public. Hypothesis' Terms of Service attribute a Creative Commons CC0 Public Domain Dedication to all public annotations. Accordingly, educators' Hypothesis usernames - some of which are anonymous - are not changed into pseudonyms in the examples below.
} 
practicing this form of critical media literacy through their own hands-on and ethically-oriented digital dialogue.

Questioning Educator Expertise

Should educators question their own expertise and, if so, how? Throughout the focal conversation, educators asked questions about their understanding of dominant media narratives, their personal media and literacy practices, as well as their own anti-racist dispositions. For example, when discussing educator responsibility to teach about racial injustice, Baker-Bell and colleagues (2018) observe, "Even the most well-intentioned educators avoid this topic [racial injustice] in their classrooms for fear of misspeaking, sounding racist, not having answers, or causing more harm than help" (148).

In response, Westerdale annotated: “I'm concerned when I hear of teachers who don't know how to hold/begin these discussions, what PD is there for those wanting to support their classrooms?" This question addresses core expertise tensions. Are educators familiar with or ignorant of sociopolitical concerns? Shouldn't educators have experience facilitating such conversation? And how would educators address a unique and consequential lack of expertise via professional learning?

This questioning of expertise - particularly about identity and equity-oriented topics indicates that an ethical stance toward digital literacy requires an honest assessment of educator practice, disposition, and participation in professional learning.

Exploring Technology Affordances

Should educators explore the social and political affordances - and consequences - of technology? The resounding response from participating educators and partner authors in this conversation was yes; yes, they should. A critical stance toward digital media literacy does not 
emerge from mere technical know-how. Rather, it can result from a sustained and careful critique of media injustice that may interrupt the reproduction of inequity. In school, Baker-Bell and colleagues (2018) propose that "a critical media literacy pedagogy can support youth in using new media genres to produce and distribute their own countermedia texts" (140).

This coupling of critical media literacy with youth "countermedia" elicited a reflective comment from cherisemcb: "So important. I would argue that one element of this 'support' is also engaging in creation with new media genres ourselves as educators and teacher educators." For cherisemcb, it is necessary for educators and teacher educators "ourselves" to explore the social and political affordances of technology through countermedia texts and new media genres. Doing so is another step forward toward an ethical and critical digital literacy stance. Creating Equitable Learning Spaces

Why must educators, as Baker-Bell and colleagues (2018) suggest, "Imagine their classrooms as spaces for healing, love, and justice" (148)?

The material and emotional spaces that define classrooms will likely change as educators develop and practice a more critical and ethical digital literacy stance. In one annotation exchange, educator andreaz reflected on the authors' call for a transformation of classroom learning spaces: "I love the image of classrooms as spaces for 'triage, self-care, healing, and social transformation.' This also means that those of us who are white teachers need to also do our work to make sure we aren't enacting our own white privilege (and thus anti-blackness) in our own practices."

For andreaz and other participants, creating a caring and healing learning environment requires that educators work against the ways in which white privilege influences pedagogy. The same awareness also applies to other personal and professional biases. Educators cannot solely 
rely upon their technological fluency if ethical practices, and especially those associated with digital literacy, are to foster equitable learning relations and spaces. Rather, educators can develop such ethical stances, and can work to transform their classrooms, through critical introspection about their privilege, presence, and pedagogy in learning spaces.

Implications for Educator Professional Learning

During the March, 2018 Marginal Syllabus conversation, karaklecheski commented: “As educators, we must teach our students how to critically analyze media and journalism." This is one important aspect of critical digital literacy. As karaklecheski's annotation asserts, there is an urgent need for educators to embrace such an ethical stance; indeed, "we must." To do so, educators should learn about digital literacy practices that evidence empathy and shared concern, that interrogate bias and power, and that work toward greater equity in educational, social, and political contexts.

In other words, educators must develop an intentional stance toward ethics, equity, and literacy. The Marginal Syllabus indicates that participation in collaborative annotation conversation is a promising means toward opening, developing, and perhaps also embracing such ethical stances. This concluding section considers how a project like the Marginal Syllabus offers implications for the design of educator professional learning oriented toward ethics, equity, and literacy.

Read Divergent Perspectives

The Marginal Syllabus invites educator to read texts that they may not typically read. These texts feature perspectives that are marginal to the status quo of schooling. The Marginal Syllabus also assumes educators have both the capacity and interest to engage with scholarship about challenging educational equity topics. 
This is an intentional and asset-based approach to professional learning that presumes educators are both curious and critical professionals. The Marginal Syllabus approaches, and then helps position, educators as learners who are eager to read divergent perspectives. To help develop their stance toward ethics, equity, and literacy, educators should read about culturally relevant pedagogy, critical literacy, youth activism, civic engagement, information accessibility, and other important and, at times, controversial topics.

Dialogue Honestly with Colleagues

As educators read about divergent and equity-oriented perspectives, they should also open up honest dialogue with their colleagues. Perhaps this means joining a project like the Marginal Syllabus. Or maybe this means starting their own online reading group or book club organized around topics and readings of shared interest. Whatever the format, it is important that educators talk with one another, share their thoughts, and ask tough questions.

Through such dialogue, educators can interrogate their biases and become more aware of their blind spots and privileges. Open and honest dialogue may even include interaction with authors, as is the case with some Marginal Syllabus conversations that invite partner authors to share about their work and participate in public annotation.

Experiment with Technology

The Marginal Syllabus encourages educator collaboration and learning through the use of open web annotation. Most educators have not heard about, much less have they experimented with, web annotation. However, web annotation draws from everyday media and annotation practices associated with reading, marking up, and commenting upon all manner of texts (Kalir and Dean 2018). Moreover, the particular web annotation tool used to mediate Marginal Syllabus dialogue - Hypothesis - is free and open-source. 
Hypothesis features an easy and low-barrier point of entry, it encourages multimodal expression, and it seamlessly allows for peer-to-peer interaction in the margins of online texts. As such, it is easy for educators to begin experimenting with a new tool, the technical genre of web annotation, and associated digital literacy practices. More broadly, professional learning oriented toward ethics, equity, and literacy should provide low-stakes opportunities for educators to experiment with new digital technologies and practices.

Foster New Dispositions

Through reading, dialogue, and experimentation with technology, professional learning should help educators to foster new dispositions toward ethics, equity, and literacy. For better or worse, technologies and associated technical skills are in constant flux. This does not absolve educators from developing new technical fluencies. It does, however, suggest that it is just as important for educators to examine and refine their dispositions, or their beliefs and values, about education.

Professional learning opportunities - like the Marginal Syllabus - might support educators as they scrutinize how digital literacy practices challenge the role and control of educators. An expansive appreciation for youth (digital) literacy practices will require that educators negotiate authority, power, and privilege inside classrooms (Christensen 2017; Haddix 2018). An inclusive and ethical approach to digital literacy requires that educators and learners equally contribute to decision-making and partner in the shared governance of their mutual learning. While technical skills are important, such a stance will require the growth and refinement of new dispositions. Design Equity-oriented Learning

Educators infrequently design their own professional learning. The Marginal Syllabus is one example of an interest-driven and openly-networked professional learning project that grew 
from the needs of educators, is facilitated by educators, and remains oriented toward educators' concerns and curiosities. Fortunately, research shows that specific design principles can help guide "generative" and equity-oriented professional learning.

For educators interested in organizing and participating in their own professional learning about ethics, equity, and literacy, they should start by focusing on teacher-identified problems of practice. Such participatory professional learning can position educators as both learners and teachers who work to develop increasingly complex questions, support collaboration despite differences in ideology and pedagogy, and connect with institutional supports (Skerrett, Warrington, and Williamson 2018).

\section{Conclusion}

Educators, like their students, learn best by doing.

This chapter has described one approach to educators shaping, pursuing, and participating in their own professional learning at the intersection of ethics, educational equity, and digital literacy. During Marginal Syllabus programming, educators read, write, and dialogue both critically and creatively about consequential educational equity topics. They do so through participation with their peers and the authors of academic scholarship, cultivating shared agency and situating professional learning in the authentic activity of conversation.

At the same time, educators-as-participants also gain fluency in the collaborative and multimodal aspects of open web annotation, both a novel technology and an attendant set of digital literacy practices. When educators participate in the Marginal Syllabus, their learning is peer-supported and also interest-driven, mediated by open technology and also oriented toward educational equity. Together, these qualities are an effective recipe for professional learning as ethical, equitable, and imbued with digital literacy. 
A goal of the Marginal Syllabus is that educators who participate in the project's public, equity-oriented annotation conversations develop a capacity to subsequently support classroom communities of ethically engaged readers and writers. It is important for learners of all ages to examine the ethical qualities of their digital literacy, to experiment with ethical practices, and to use digital literacy practices to critique circumstances that are unethical and inequitable. For learners across grades and disciplines to do so, educators must model such practices as informed by their own learning experiences.

Equity-oriented professional learning mediated by open web annotation advances agentive social reading and dialogue across educational texts and contexts. This model is relevant to both professional learning and classroom settings, and thrives at the intersection of ethics, equity, and literacy.

\section{References}

Baker-Bell, April, Raven Jones Stanbrough, and Sakeena Everett. "The stories they tell: Mainstream media, pedagogies of healing, and critical media literacy." English Education 49 no. 2 (2018): 130-152.

Christensen, Linda. "Critical literacy and our students' lives.” Voices from the Middle 24 no. 3 (2017): 16-19.

Daniels, Harvey. Literature Circles: Voice and Choice in Book Clubs and Reading Groups (2 ed.). Portland: Stenhouse, 2002.

Haddix, Marcelle. "What's radical about youth writing?: Seeing and honoring youth writers and their literacies." Voices From the Middle 25 no. 3 (2018): 8-12.

Kalir, Jeremiah. "Equity-oriented design in open education.” International Journal of Information and Learning Technology 35, no. 5 (2018): 357-367. 
Kalir, Jeremiah, and Jeremy Dean. "Web annotation as conversation and interruption." Journal of Media Practice 19, no. 1 (2018): 18-29.

Kalir, Jeremiah, and Francisco Perez. "The Marginal Syllabus: Educator learning and web annotation across sociopolitical texts and contexts." In Marginalia in Modern Learning Contexts, edited by Alan Reid, 17-58. Hershey: IGI Global, 2019.

Mirra, Nicole. "Pursuing a commitment to public scholarship through the practice of annotation." The Assembly, 1: 2018.

Morris, Sean Michael and Jesse Stommel. An Urgency of Teachers: The Work of Critical Digital Pedagogy. Hybrid Pedagogy Inc., 2018.

Shresthova, Sangita. "Between storytelling and surveillance: The precarious public of American Muslim Youth.” In By Any Media Necessary: The New Youth Activism, edited by Henry Jenkins, Sangita Shresthova, Liana Gamber-Thompson, Neta Kligler-Vilenchik, and Arely Zimmerman. New York: New York University Press, 2016.

Skerrett, Allison, Amber Warrington, and Thea Williamson. "Generative principles for professional learning for equity-oriented urban English teachers." English Education 50 no. 2 (2018): 116-146.

Watulak, Sarah, Rebecca Woodard, Anna Smith, Lindy Johnson, Nathan Phillips, and Katalin Wargo. "Connected teaching and learning in K-16+ contexts: An annotated bibliography." Contemporary Issues in Technology and Teacher Education 18 no. 2 (2018): 289-312.

\section{About the Authors}

Jeremiah (Remi) Kalir is Assistant Professor of Learning Design and Technology at the University of Colorado Denver School of Education and Human Development. Kalir is a co- 
founder and facilitator of the Marginal Syllabus project, and is a former middle school teacher. Kalir's current research about educator learning through collaborative web annotation was supported by a 2017-18 OER Research Fellowship from the Open Education Group and a 2016 National Science Foundation Data Consortium Fellowship. He has also served as chair of the American Educational Research Association's Media, Culture, and Learning Special Interest Group, as Co-PI of ThinqStudio, CU Denver's digital pedagogy incubator, and as a board member of InGlobal Learning Design.

Joe Dillon teaches English 11 and English Language Acquisition at Rangeview High School in Aurora, CO, where he also works with teachers as an instructional coach. This is his 14th year in public education and in that time he's been a literacy teacher leader and a teacher coach for grades K-12. He worked for four years as the instructional coordinator for educational technology in the Aurora Public Schools, supporting schools with technology integration plans. He holds a Bachelor's Degree in English from CU Boulder and a Master's Degree in Curriculum and Instruction from the University of Colorado Denver. Joe frequently collaborates with the Denver Writing Project and the National Writing Project, leading professional learning across Colorado's Front Range, teaching writing workshops for young writers, and facilitating online professional learning projects that attract a global audience. 